\title{
Modulation of Voltage-Gated Sodium Channels by Activation of Tumor Necrosis Factor Receptor-1 and Receptor-2 in Small DRG Neurons of Rats
}

\author{
M. Leo, S. Argalski, M. Schäfers, and T. Hagenacker \\ Department of Neurology, University of Duisburg-Essen, Germany \\ Correspondence should be addressed to T. Hagenacker; tim.hagenacker@uk-essen.de
}

Received 2 July 2015; Revised 10 August 2015; Accepted 18 August 2015

Academic Editor: Mauricio Retamal

Copyright (C) 2015 M. Leo et al. This is an open access article distributed under the Creative Commons Attribution License, which permits unrestricted use, distribution, and reproduction in any medium, provided the original work is properly cited.

\begin{abstract}
Tumor necrosis factor- (TNF-) $\alpha$ is a proinflammatory cytokine involved in the development and maintenance of inflammatory and neuropathic pain. Its effects are mediated by two receptors, TNF receptor-1 (TNFR-1) and TNF receptor-2 (TNFR-2). These receptors play a crucial role in the sensitization of voltage-gated sodium channels (VGSCs), a key mechanism in the pathogenesis of chronic pain. Using the whole-cell patch-clamp technique, we examined the influence of TNFR-1 and TNFR-2 on VGSCs and TTXresistant NaV1.8 channels in isolated rat dorsal root ganglion neurons by using selective TNFR agonists. The TNFR- 1 agonist R32W $(10 \mathrm{pg} / \mathrm{mL})$ caused an increase in the VGSC current $\left(I_{\mathrm{Na}(\mathrm{V})}\right)$ by $27.2 \pm 5.1 \%$, while the TNFR-2 agonist D145 $(10 \mathrm{pg} / \mathrm{mL})$ increased the current by $44.9 \pm 2.6 \%$. This effect was dose dependent. Treating isolated NaV1.8 with R32W $(100 \mathrm{pg} / \mathrm{mL})$ resulted in an increase in $I_{\mathrm{NaV}(1.8)}$ by $18.9 \pm 1.6 \%$, while treatment with D145 $(100 \mathrm{pg} / \mathrm{mL})$ increased the current by $14.5 \pm 3.7 \%$. Based on the current-voltage relationship, $10 \mathrm{pg}$ of R32W or D145 led to an increase in $I_{\mathrm{Na}(\mathrm{V})}$ in a bell-shaped, voltage-dependent manner with a maximum effect at $-30 \mathrm{mV}$. The effects of TNFR activation on VGSCs promote excitation in primary afferent neurons and this might explain the sensitization mechanisms associated with neuropathic and inflammatory pain.
\end{abstract}

\section{Introduction}

Tumor necrosis factor- (TNF-) $\alpha$ is a proinflammatory cytokine that is expressed by a variety of cell types, such as immune or neuronal cells. TNF is involved in the development and maintenance of inflammatory and neuropathic pain $[1,2]$. However, the mechanisms by which TNF elicits neuropathic pain are not fully understood. The effects of TNF are mediated by two distinct receptor subtypes, TNFR-1 and TNFR-2, which colocalize in nucleated cells $[3,4]$. Both TNF and its receptors are expressed in rat dorsal root ganglion (DRG) neurons and are upregulated after nerve injury [5, 6]. In vivo application of TNF to DRG neurons induces pain-related behavior in rats [6], which is accompanied by mechanical and thermal hyperalgesia. These pain-inducing effects are prevented by preemptively using TNF-neutralizing agents $[7,8]$ or by inhibiting the TNF-signaling pathway [6]. In addition, TNF influences neuronal excitability by increasing voltage-gated sodium channel (VGSC) currents
$\left(I_{\mathrm{Na}(\mathrm{V})}\right)$, which promotes action potential generation and may maintain neuropathic pain [9]. Local application of TNF to nociceptive neurons evokes action potentials and increases discharge rates of nerve fibers [10]. Tetrodotoxin- (TTX-) resistant NaV1.8 channel currents $\left(I_{\mathrm{NaV}(1.8)}\right)$, which are essential in the pathogenesis of neuropathic pain, are increased by a TNF-mediated MAP kinase-dependent pathway in DRG neurons [11, 12]. Furthermore, the lack of TNFR-1 in TNFR- $1^{-/-}$mice led to reduced mechanical hypersensitivity, which is induced by exogenous TNF or inflammation [13]. Neutralizing antibodies against TNFR- 1 also reduced thermal or mechanical hypersensitivity induced by nerve injury, while antibodies against TNFR-2 were ineffective [14]. These results suggest a crucial role for TNFR-1, but not TNFR-2, in the sensitization of VGSCs [12].

In the present study, we examined the influence of TNFR1 and TNFR-2 on the modulation of $I_{\mathrm{Na}(\mathrm{V})}$ and $I_{\mathrm{NaV}(1.8)}$ in rat DRG neurons by using selective TNFR agonists. 


\section{Methods}

2.1. Animals. Adult male Wistar rats (3 weeks old, $80-120 \mathrm{~g}$ ) were used. All experiments were performed in accordance with the guidelines of the Animal Care and Use Committees of the University of Duisburg-Essen, Germany. All animals were kept on a 14/10 h light/dark cycle with water and food pellets available ad libitum.

2.2. Selective TNF Receptor Agonists. TNF mutant proteins were used (given by the P. Vandenabeele Lab, Ghent, Belgium) for the selective stimulation of either TNFR-1 or TNFR-2. The R32W and D145 proteins contain double mutations (R32W/S86T and D143N/A145R, resp., $[15,16])$ and can selectively activate rat TNFR-1 and TNFR-2, respectively [17]. Mutated TNF proteins R32W and D145 have been extensively tested and showed differential binding to purified TNF receptors. The binding studies have been confirmed by biological assays using either TNFR-1 or TNFR-2 [16]. Each receptor-specific protein was dissolved in an ACSF vehicle containing $0.1 \%$ bovine serum albumin (BSA).

2.3. Cell Culture. DRG neurons were isolated from 3-weekold Wistar rats. The animals were anaesthetized with isoflurane. In the absence of pain reflexes, the animals were decapitated. The spinal column was removed and opened from the dorsal side. After dissection of the spinal cord, the DRGs were collected and placed in ice cold F12 media (Biochrom AG, Germany). Under optic control, the spinal nerves were cut off and the ganglion capsules were opened. The capsules were transferred into a medium containing $0.9 \mathrm{~mL}$ of $\mathrm{F} 12$ and $0.1 \mathrm{~mL}$ of collagenase $(2612.5 \mathrm{U} / \mathrm{mL}$, Type II, Biochrom AG, Germany) and incubated for $45 \mathrm{~min}$ in a humidified atmosphere containing $5 \% \mathrm{CO}_{2}$ at a temperature of $37^{\circ} \mathrm{C}$. To remove the collagenase, the DRGs were washed three times in $1 \mathrm{~mL}$ of F12 medium. Afterwards, the DRGs were trypsinized ( $2525 \mathrm{U}$ trypsin/mL F12 medium) for $2 \mathrm{~min}$ under the same conditions. DRGs were washed twice, left in a final volume of $0.7 \mathrm{~mL}$ of F12 medium, and triturated with a pipette until the neurons were released. A total of $50 \mu \mathrm{L}$ of this suspension was placed in the middle of each Petri dish $(3 \mathrm{~cm}$, Falcon Easy Grip). Cells were incubated for at least $2 \mathrm{~h}$ so that the neurons could adhere to the dish, and then $1 \mathrm{~mL}$ of medium containing F12 and 10\% horse serum (Biochrom AG, Germany) was added to each dish.

2.4. Electrophysiology. $I_{\mathrm{Na}(\mathrm{V})}$ and $I_{\mathrm{NaV}(1.8)}$ were isolated by performing the whole-cell patch-clamp technique using HEKA EPC 10 amplifier with Patchmaster software (HEKA Electronics, Germany). Only cells with a small diameter < $30 \mu \mathrm{m}$ were chosen. Microelectrodes, consisting of borosilicate glass (Biomedical Instruments), were pulled with a HEKA Pipette Puller (PIP6, HEKA Electronics, Germany) and were fire polished to a final resistance of $4-5 \mathrm{M} \Omega$ by using a microforge (Narishige, Japan). This relatively high resistance was intentionally chosen to guarantee the necessary stable configuration during the course of the experiments. Although it is possible that this configuration can have a negative effect on the electrodes' ability to pass sufficient current, especially at peak currents while maintaining a current-voltage relationship ( $I V$-curve), this configuration allowed us to analyze the underlying mechanisms that have small effects on the current.

Before starting experiments, F12 culture medium was replaced by an external solution containing $72 \mathrm{mM} \mathrm{NaCl}$, $72 \mathrm{mM}$ choline- $\mathrm{Cl}, 2.5 \mathrm{mM} \mathrm{KCl}, 10 \mathrm{mM}$ HEPES, $10 \mathrm{mM}$ glucose, and $50 \mu \mathrm{M} \mathrm{CdCl}$ and adjusted to $\mathrm{pH}$ of 7.4 with $\mathrm{NaOH}$. The internal pipette solution contained $140 \mathrm{mM} \mathrm{CsCl}, 5 \mathrm{mM}$ $\mathrm{NaCl}, 10 \mathrm{mM}$ HEPES, $10 \mathrm{MM}$ EGTA, and $4 \mathrm{mM} \mathrm{MgCl} 2$ and was adjusted to $\mathrm{pH}$ of 7.2 with TEA-OH.

The $I V$-curve for $I_{\mathrm{Na}(\mathrm{V})}$ was recorded for depolarizing steps starting at $-60 \mathrm{mV}$ and increased stepwise by $10 \mathrm{mV}$ to maximum depolarization of $+60 \mathrm{mV}$ after hyperpolarizing prepulse to $-120 \mathrm{mV}$ for $500 \mathrm{~ms}$ to recover sodium channels from state of inactivation. Application of the drugs started after obtaining $2 I V$-curves under control conditions. For time course experiments, TNFR agonists were applied after 10 control depolarization procedures. NaV1.8 currents were isolated after eliminating tetrodotoxin-sensitive currents using $500 \mathrm{nM}$ tetrodotoxin in the external solution and maintaining a $-80 \mathrm{mV}$ potential, which efficiently eliminates the persistent tetrodotoxin-resistant NaV1.9 current as shown before [18, 19]. $I V$-curves of isolated NaV1.8 currents were similar to other curves described elsewhere [20]. The somata of the small DRG neurons were classified by their diameters (15 $30 \mu \mathrm{m})$ and $C_{m}(\leq 45 \mathrm{pF})$. Neurons were not considered for analysis if they had high leakage currents (holding current $>1.0 \mathrm{nA}$ at $-80 \mathrm{mV}$ ), membrane blebs, total sodium current $<500 \mathrm{pA}$, or access resistance $>5 \mathrm{M} \Omega$. Access resistance was monitored throughout the experiment and data were not used if resistance changes of $>20 \%$ occurred. The offset potential was zeroed before patching the cells and checked after each recording for drift. Data were sampled at $10 \mathrm{kHz}$, compensated for series resistance, and stored on hard disk.

2.5. Data Analysis. All currents were online corrected by using a $\mathrm{P} / 4$ protocol. All $I_{\mathrm{Na}(\mathrm{V})}$ used for the time course and current-voltage relationships were rundown corrected assuming linear rundown. Current values were standardized to the mean current before application of the drugs ( $=100 \%)$. For calculation of the mean current, 20 data points were used. The nonresponders were given a value of 0 in the calculation determining the current increase.

2.6. Statistical Analysis. All data are given as the mean +/standard deviation. Data were analyzed by using doublesided Student's $t$-test. A difference was accepted as significant if $p<0.05$.

\section{Results}

$I_{\mathrm{Na}(\mathrm{V})}$ was successfully recorded from 112 DRG neurons. Cells were classified as responders if the current was changed by at least $10 \%(n=71)$. Depolarization of DRG neurons from the holding potential to $0 \mathrm{mV}$ led to an inwardly directed, inactivating current. Administration of the dissolving agents 


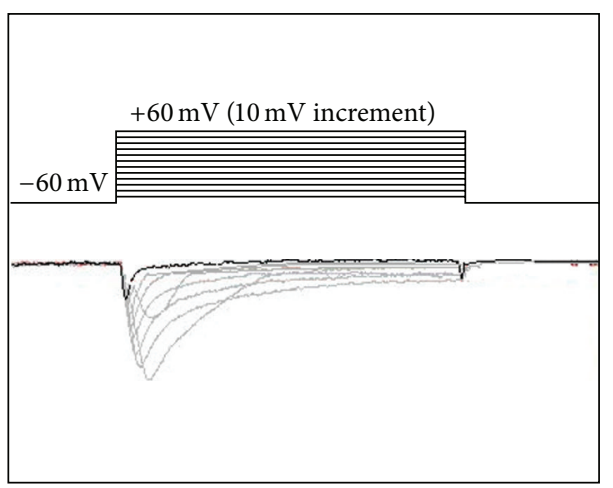

(a)

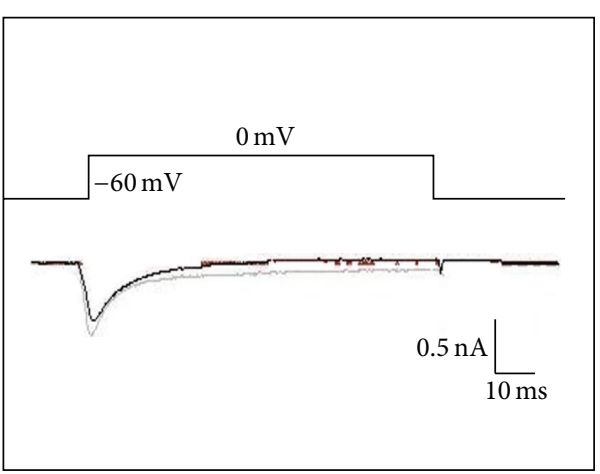

(c)

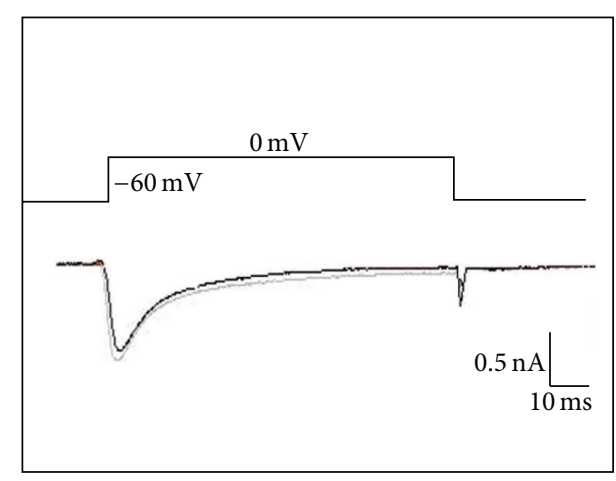

(e)

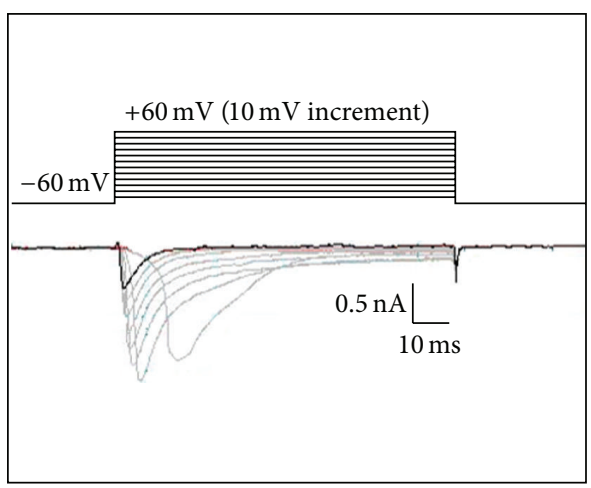

(b)

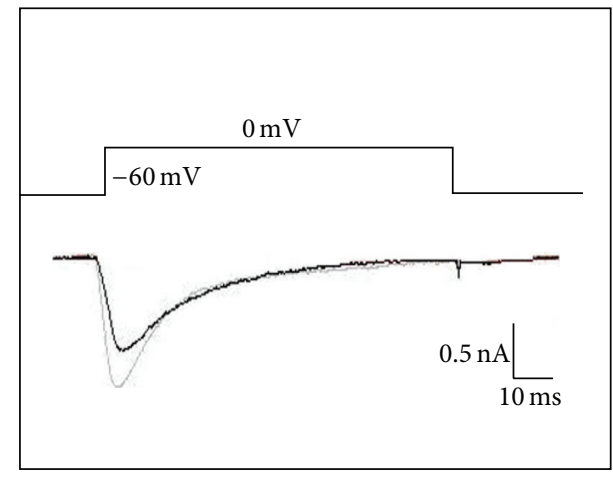

(d)

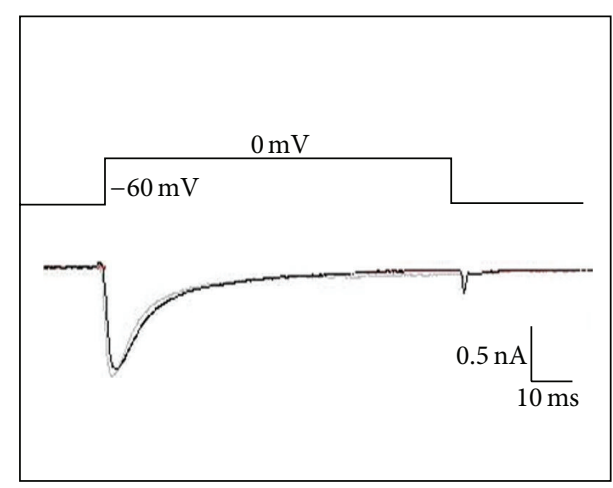

(f)

FiguRE 1: Representative traces of VGSCs. Cells were depolarized to a variety of membrane potentials ((a) $I_{\mathrm{Na}(\mathrm{V})}$ and (b) $\left.I_{\mathrm{Na}(\mathrm{V} 1.8)}\right) . I_{\mathrm{Na}(\mathrm{V})}$ currents before (black) and after (gray) application of $10 \mathrm{pg} \mathrm{R} 32 \mathrm{~W}$ (c) and D145 (d). $I_{\mathrm{Na} \text { (V1.8) }}$ currents before (black) and after (gray) application of $100 \mathrm{pg}$ R32W (e) and D145 (f).

$(\mathrm{ACSF}+0.1 \% \mathrm{BSA})$ does not change the currents (data not shown). Treatment of DRG neurons with either R32W or D145 led to an increase of $I_{\mathrm{Na}(\mathrm{V})}$ and $I_{\mathrm{NaV}(1.8)}$ (Figures $1(\mathrm{a})$ and 1(b)).

Application of R32W (10 pg) led to an increase of $I_{\mathrm{Na}(\mathrm{V})}$ by $27.2 \pm 5.1 \%$. A steady state current was reached after $415 \mathrm{~s}$ $(n=11)$. Application of D145 $(10 \mathrm{pg})$ increased $I_{\mathrm{Na}(\mathrm{V})}$ by $44.9 \pm 2.6 \%$, reaching a steady state after $500 \mathrm{~s}(n=8)$. During the washout, the currents return to almost baseline $(111.45 \pm 8.5 \%$ versus $112.87 \pm 7.6 \%)$ (Figure $2(\mathrm{a})$ ).
In the $I V$-curve, a maximum current was elicited at depolarization to $-30 \mathrm{mV}$. R32W and D145 increased the current in a bell-shaped voltage-dependent manner in the range between $-50 \mathrm{mV}$ and $+60 \mathrm{mV}(n=10$ each). Reversal potentials were at $+50 \mathrm{mV}$ and were not changed by the application of D145 or R32W (Figures 2(b) and 2(c)).

During repetitive depolarization procedures to $0 \mathrm{mV}$, application of either R32W (100 pg) $(n=8)$ or D145 (100 pg) $(n=8)$ led to an increase in $I_{\mathrm{NaV}(1.8)}$ by $18.9 \pm 1.6 \%$ and $14.5 \pm 3.7 \% 300 \mathrm{~s}$ after treatment, respectively (Figure 2(d)). 


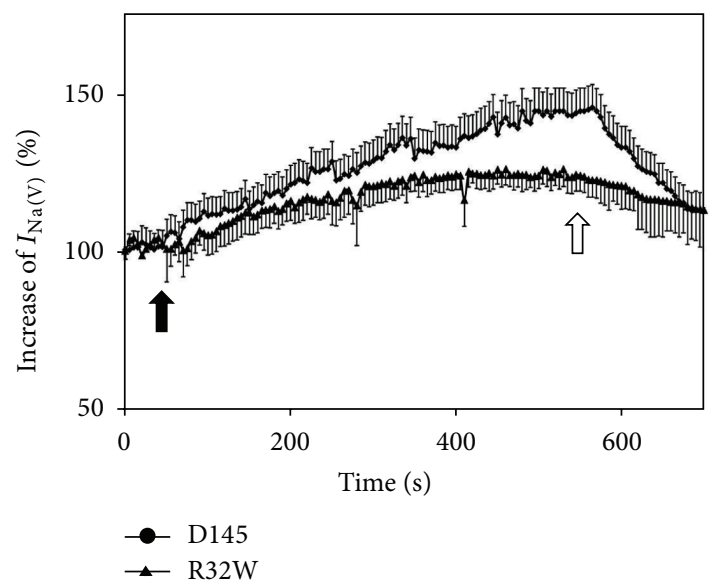

(a)

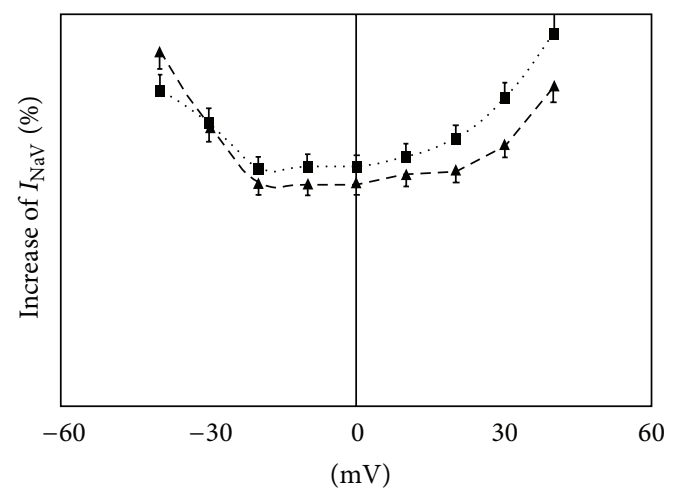

- D145

-. $\mathrm{R} 32 \mathrm{~W}$

(c)

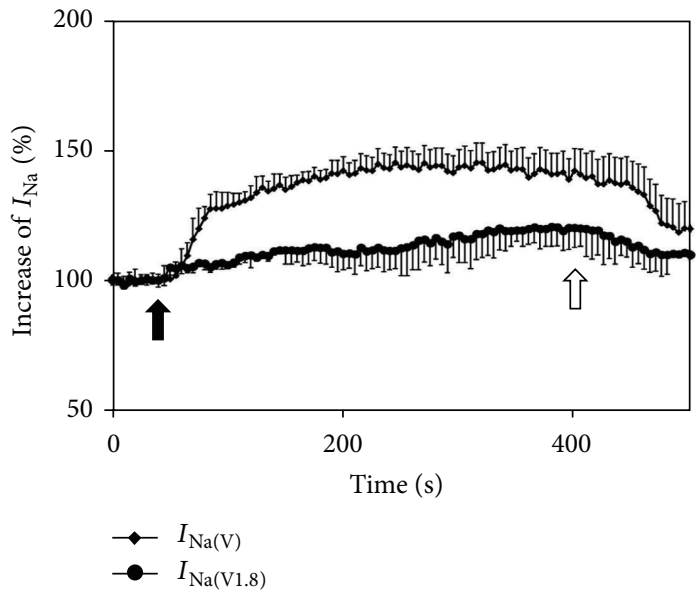

(e)

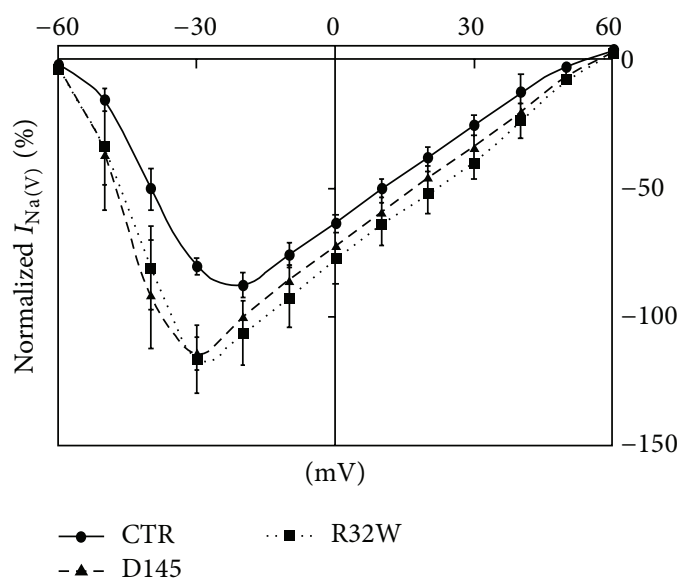

(b)

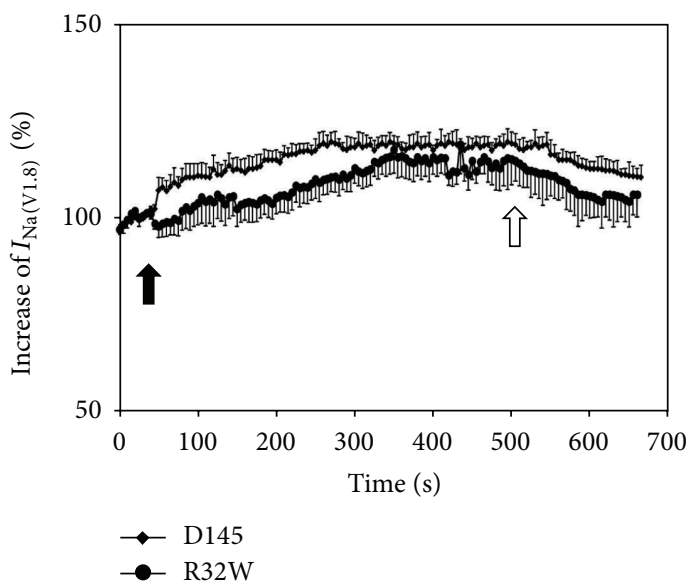

(d)

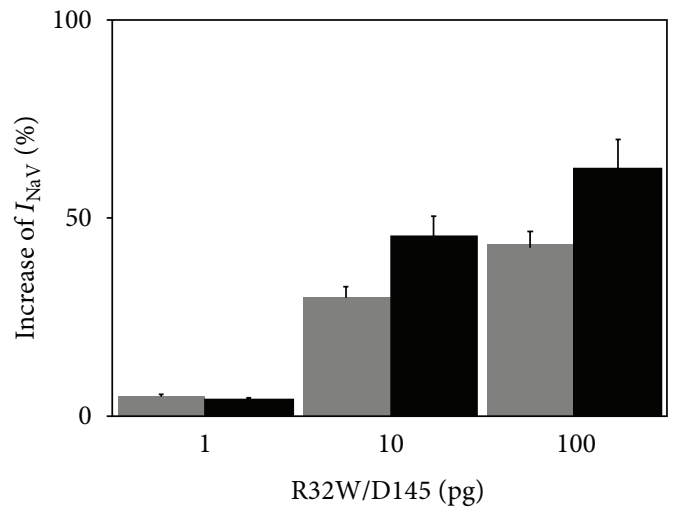

(f)

FIGURE 2: Characterization of R32W and D145 effects on $I_{\mathrm{Na}(\mathrm{V})}$ and $I_{\mathrm{Na}(\mathrm{V} 1.8)}$ currents. (a) Time course of normalized $I_{\mathrm{Na}(\mathrm{V})}$ during repetitive depolarization from the holding potential to $0 \mathrm{mV}$ before and after application of $10 \mathrm{pg}$ R32W or $10 \mathrm{pg}$ D145 (black arrow: time of application; white arrow: washout). (b) $I V$-curve of $I_{\mathrm{Na}(\mathrm{V})}$ (black: control conditions; speckled line: after application of $10 \mathrm{pg}$ R32W; dashed line: after application of $10 \mathrm{pg}$ D145). Cells were depolarized to a variety of potentials ( -60 to $60 \mathrm{mV}$ ) from a holding potential of $-80 \mathrm{mV}$ at increments of $10 \mathrm{mV}$ to elicit $I_{\mathrm{Na}(\mathrm{V})}$. (c) Voltage-dependent reduction of $I_{\mathrm{Na}(\mathrm{V})}$ after administration of $10 \mathrm{pg}$ R32W or $10 \mathrm{pg}$ D145. (d) Time course of normalized $I_{\mathrm{Na}(\mathrm{V} 1.8)}$ during repetitive depolarization from the holding potential to $0 \mathrm{mV}$ before and after application of $100 \mathrm{pg}$ R32W or $100 \mathrm{pg}$ D145 (black arrow: time of application; white arrow: washout). (e) Time course of normalized $I_{\mathrm{Na}(\mathrm{V})}$ and $I_{\mathrm{Na}(\mathrm{V} 1.8)}$ during repetitive depolarization from the holding potential to $0 \mathrm{mV}$ before and after application of $10 \mathrm{pg}$ R32W and $10 \mathrm{pg}$ D145 (black arrow: time of application; white arrow: washout). (f) R32W and D145 dose-dependent increase in $I_{\mathrm{Na}(\mathrm{V})}$. 


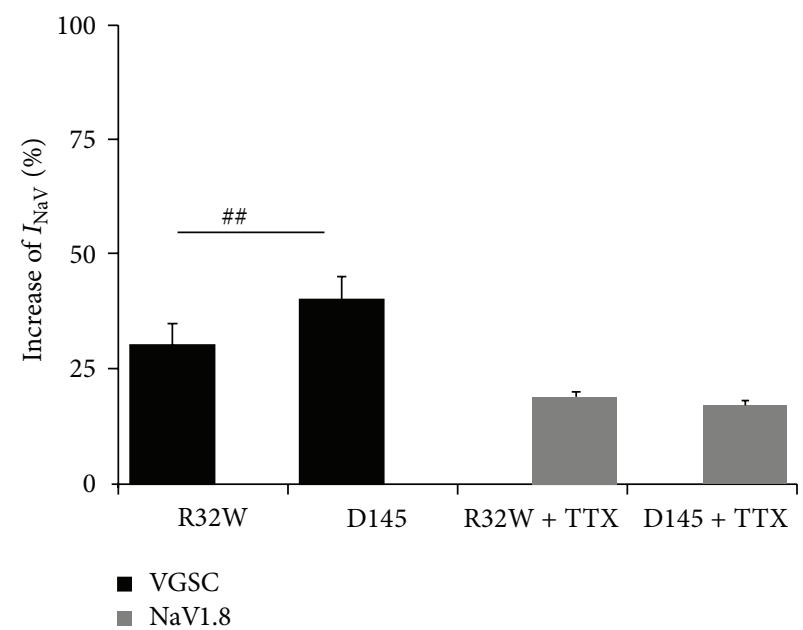

(a)

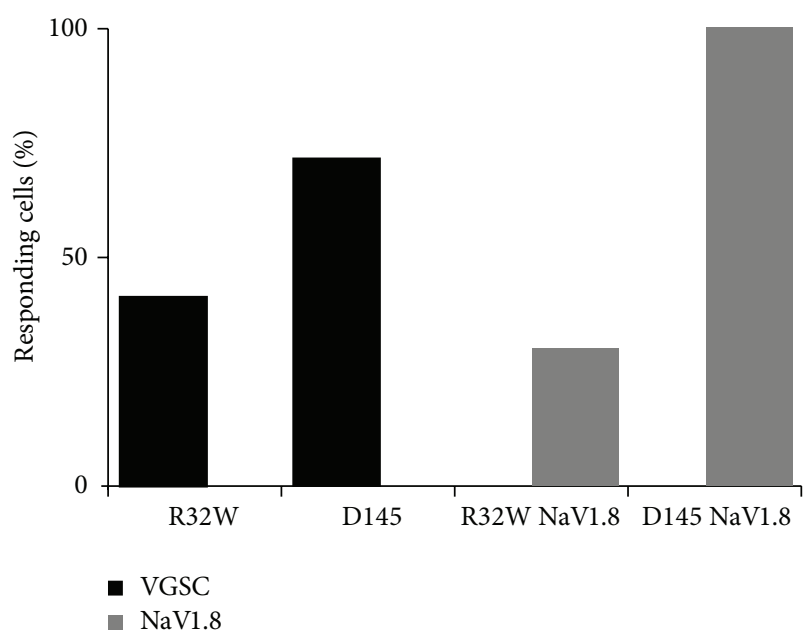

(b)

FiguRE 3: (a) Increase in $I_{\mathrm{Na}(\mathrm{V})}$ (10 pg of each drug) and $I_{\mathrm{Na}(\mathrm{V} 1.8)}$ (100 pg of each drug) currents after application of R32W or D145 during repetitive depolarization to $0 \mathrm{mV}$ after $600 \mathrm{~s}$ when the current reaches a steady state $\left({ }^{\# \#} p<0.01\right)$. (b) Amount of responding cells, including $I_{\mathrm{Na}(\mathrm{V})}$ or $I_{\mathrm{Na}(\mathrm{V} 1.8)}$, in the cell population. Cells were classified as responding cells if the currents were affected by more than $10 \%$.

The dual application of R32W and D145 (100 pg) led to an increase of $I_{\mathrm{Na}(\mathrm{V})}$ by $45.2 \pm 7.4 \% 320 \mathrm{~s}$ after treatment $(n=7)$, while $I_{\mathrm{NaV}(1.8)}$ was increased by $20.6 \pm 6.8 \% 400 \mathrm{~s}$ after application $(n=7)$ during repetitive depolarization to $0 \mathrm{mV}$ (Figure 2(e)).

Using increasing concentrations of R32W or D145 (1$100 \mathrm{pg}$ ) led to an increase of $I_{\mathrm{Na}(\mathrm{V})}$ in a dose-dependent manner (Figure 2(f)).

Application of D145 (10 pg) led to significantly higher increase of $I_{\mathrm{Na}(\mathrm{V})}$ compared to the application of $\mathrm{R} 32 \mathrm{~W}$ $(10 \mathrm{pg})$. Treatment with either $100 \mathrm{pg}$ of D145 or R32W led to a significantly higher increase of $I_{\mathrm{Na}(\mathrm{V})}$ compared to $I_{\mathrm{NaV}(1.8)}$ (Figure 3(a)). In both settings, when measuring isolated $I_{\mathrm{Na}(\mathrm{V})}$ and $I_{\mathrm{NaV}(1.8)}$, the amount of responding cells was higher using D145 than R32W (Figure 3(b)).

\section{Discussion}

This study presents evidence for differential modulation of VGSC and the TTX-resistant subtype NaV1.8 by TNFR in small DRG neurons. TNF has been shown to regulate a variety of ion channels. It decreases potassium channel currents in retinal ganglion neurons [21] and increases calcium channel currents in hippocampal and cultured superior cervical ganglion neurons $[22,23]$. In DRG neurons, a decrease of voltage-gated calcium channel currents and an increase in $I_{\mathrm{Na}(\mathrm{V})}$ have been described, while voltage-gated potassium channel currents were not affected, suggesting that TNF has differential effects depending on the ion channel and cell type [9]. An increase in $I_{\mathrm{Na}(\mathrm{V})}$ may promote hyperexcitability, which is a key symptom of neuropathic pain. Besides the long-lasting effects of TNF by regulating the expression of a variety of inflammatory mediators and modifying signaling proteins, the application of TNF has rapid onset effects, which suggest interactions with primary excitation proteins such as VGSC. The enhancement of TTX-resistant VGSC currents starts in $<60 \mathrm{~s}$ and the enhancement of VGSC currents in DRG neurons begins within $20 \mathrm{~s}$ after TNF administration $[9,12,24]$. Using in vitro single-fiber recordings for isolating $\mathrm{A} \delta$ - and C-fiber activity in DRG neurons, perfusion with TNF increases rapid firing rates, also suggesting a direct interaction between VGSCs and TNF [25]. Variations in TNF responses exist but can be explained by technical reasons, that is, distance from application pipette to the neuron. Interestingly, the increase in $I_{\mathrm{Na}(\mathrm{V})}$ is higher when using selective agonists compared to the use of TNF alone. In other systems, TNF has been shown to reduce $I_{\mathrm{Na}(\mathrm{V})}$ via a PKC-dependent pathway, which may counteract effects on VGSC via other signaling pathways [26]. This can explain why TNF mediates different effects compared to the selective agonists alone. The application of TNF to DRG neurons induces mechanical allodynia and mechanical sensitivity of C-fibers $[27,28]$. These results suggest an important role for the interaction of TNF and VGSC.

TNF promotes its effects via the constitutively expressed TNFR-1 and the inducible TNFR-2. Different intracellular signal pathways are affected by TNFR-1 and TNFR-2 activation. While TNFR-1 activation leads to internalization of the receptor, TNFR-2 activation is followed by shedding of the ligand-receptor complex [29]. Consequently, TNFR activation elicits distinct effects. For example, it has been shown that activation of TNFR-1 by local application of TNF to naïve DRGs induced high-frequency firing of $\mathrm{A} \beta$ - and $\mathrm{A} \delta$ fibers, while TNFR-2 activation had no effect. In contrast, after nerve injury, both TNFR-1 and TNFR-2 activation increased discharge rates [25]. TNFR-1 seems to be very important in the pain-sensitizing actions of TNF. Mechanical hypersensitivity induced by inflammation or nerve injury is reduced in TNFR-1 knockout mice [13]. In addition, neutralizing antibodies against TNFR-1 reduced pain-associated behavior, while antibodies against TNFR-2 were noneffective [14]. These results underlie the different roles of TNFR-1 and 
TNFR-2 in pathologic conditions and offer the possibility to target neuropathic pain.

In contrast to previous studies, our results showing that there is a larger increase of $I_{\mathrm{Na}(\mathrm{V})}$ after activation of TNFR-2 and an increase in reacting cells provide evidence that TNFR2 has a more important role than TNFR- 1 in the modulation of nerve excitability. The higher rate of responding cells when isolating $I_{\mathrm{NaV}(1.8)}$ is surprising. A possible reason for this higher rate may be that the membrane-bound receptors are coexpressed. It is possible that the activation of TNFR1/TNFR-2 leads to higher response rates when coexpressed with NaV1.8 in comparison to neurons that coexpress TNFRs with other isoforms of NaV. The coexpression of TNFR and $\mathrm{NaV}$ isoforms has been shown for NaV1.7 in DRG neurons and chromaffin cells [30]. In addition, the expression of TNFR-2 has been shown to be closely related to NaV1.7 and NaV1.8 expression in sensory neurons, which may explain the predominant responding rates of D145 compared to R32W [31]. This effect may be important in the initial phase of inflammatory and neuropathic pain but may be superimposed by the changes in the pattern of expression of TNFR- 1 and TNFR-2 after nerve injury and explain the effects of TNFR- 1 and TNFR- 2 seen in other studies, especially after nerve injury $[6,25]$. The shift in the $I V$-curve and the increase of $I_{\mathrm{Na}(\mathrm{V})}$ in the voltage above $0 \mathrm{mV}$ may be explained by an increase of the available channels or an increase in channel permeability.

Several intracellular pathways have to be examined for downstream signaling of TNFR activation. VGSCs have various phosphorylation sites, on which modification may lead to changes in the biophysical properties of channel gating. Recently, chelerythrine has been shown to suppress the inhibitory effect of TNF on sodium channel currents of skeletal muscle cells, suggesting the involvement of protein kinase C (PKC) in regulation of VGSC $[26,32]$. In addition, it is known that modulation of VGSCs is dependent on the special channel subtype [33]. It has been shown that the activation of TNFR-1 increases $I_{\mathrm{NaV}(1.8)}$ rapidly in mouse DRG neurons by p38-dependent mechanisms [12]. p38 may enhance $I_{\mathrm{NaV}(1.8)}$ by phosphorylating the NaV1.8 channel or an associated protein. In addition, p38 has been shown to directly modulate other voltage-gated channels [34]. In inflammatory responses, NF- $\kappa \mathrm{B}$ has been shown to be involved in TNF-mediated ion channel regulation [35]. Pathways with common final targets are possible due to the observation that the dual application of TNFR agonists has no additive effect on $I_{\mathrm{Na}(\mathrm{V})}$ or $I_{\mathrm{NaV}(1.8)}$. The possibility of TNFR-subtype dependent signaling pathways will have to be addressed in further studies.

The limitations of our study need to be discussed. Because the mutant peptides were designed to target human TNFR, we cannot exclude the possibility that there are different effects in rat DRGs. However, the cross-reactivity of our mutants has been established before using a cell death assay [36]. The efficacy of the mutants may differ in TNFR-1 and TNFR-2. Our study only uses naïve DRG neurons. Because of the several pathways activated after nerve injury, our results concerning TNF as well as other inflammatory mediators or posttranslational modification of ion channel activity may be limited by long-lasting superimposing effects. We only used in vitro techniques; hence, the results may translate to in vivo effects. Another aspect to consider is the expression rate of TNFR- 1 and TNFR-2 in nociceptive neurons. In our study, we found a responding rate of $\sim 60 \%$ in all experiments. Other studies of mouse and rat DRG have shown that TNFR-1 or TRPV1 is expressed in up to $40 \%$ of the sensory neurons. Most of the TRPV1-expressing neurons coexpress isolectinB4. While $>30 \%$ of these neurons coexpress TNFR- 1 and TRPV1, only $10 \%$ of the neurons coexpress both TNFR and IB4 [37]. In small sized DRG neurons $(\sim 30 \mu \mathrm{m})$, TRPV1 is expressed in $\sim 50 \%$ of the cell population [38]. To our knowledge, the coexpression rates of TNFR- 2 and TRPV1 or IB4 have not been described. This may explain the differential effects of TNFR agonists in different cell populations. Further experiments have be designed to determine whether this is the case.

In conclusion, our study provides evidence for a potential role of TNFR-2 in the generation of hyperexcitability by increasing of VGSC currents in uninjured (or peracute injured) neurons, which may be a relevant mechanism in neuropathic and inflammatory pain conditions.

\section{Conflict of Interests}

The authors declare that there is no conflict of interests regarding the publication of this paper.

\section{References}

[1] C. Sommer and M. Kress, "Recent findings on how proinflammatory cytokines cause pain: peripheral mechanisms in inflammatory and neuropathic hyperalgesia," Neuroscience Letters, vol. 361, no. 1-3, pp. 184-187, 2004.

[2] E. K. Joseph and J. D. Levine, "Caspase signalling in neuropathic and inflammatory pain in the rat," European Journal of Neuroscience, vol. 20, no. 11, pp. 2896-2902, 2004.

[3] P. Vandenabeele, W. Declercq, R. Beyaert, and W. Fiers, "Two tumour necrosis factor receptors: structure and function," Trends in Cell Biology, vol. 5, no. 10, pp. 392-399, 1995.

[4] D. J. MacEwan, "TNF receptor subtype signalling: differences and cellular consequences," Cellular Signalling, vol. 14, no. 6, pp. 477-492, 2002.

[5] P. G. Murphy, J. Grondin, M. Altares, and P. M. Richardson, "Induction of interleukin-6 in axotomized sensory neurons," Journal of Neuroscience, vol. 15, no. 7, part 2, pp. 5130-5138, 1995.

[6] M. Schäfers, L. S. Sorkin, C. Geis, and V. I. Shubayev, "Spinal nerve ligation induces transient upregulation of tumor necrosis factor receptors 1 and 2 in injured and adjacent uninjured dorsal root ganglia in the rat," Neuroscience Letters, vol. 347, no. 3, pp. 179-182, 2003.

[7] T. Lindenlaub, P. Teuteberg, T. Hartung, and C. Sommer, "Effects of neutralizing antibodies to TNF-alpha on painrelated behavior and nerve regeneration in mice with chronic constriction injury," Brain Research, vol. 866, no. 1-2, pp. 15-22, 2000.

[8] S. Sweitzer, D. Martin, and J. A. DeLeo, "Intrathecal interleukin1 receptor antagonist in combination with soluble tumor necrosis factor receptor exhibits an anti-allodynic action in a rat 
model of neuropathic pain," Neuroscience, vol. 103, no. 2, pp. 529-539, 2001.

[9] J. C. Czeschik, T. Hagenacker, M. Schäfers, and D. Büsselberg, "TNF- $\alpha$ differentially modulates ion channels of nociceptive neurons," Neuroscience Letters, vol. 434, no. 3, pp. 293-298, 2008.

[10] L. S. Sorkin, W.-H. Xiao, R. Wagner, and R. R. Myers, “Tumour necrosis factor- $\alpha$ induces ectopic activity in nociceptive primary afferent fibres," Neuroscience, vol. 81, no. 1, pp. 255-262, 1997.

[11] G. Bhave and R. W. Gereau IV, "Posttranslational mechanisms of peripheral sensitization," Journal of Neurobiology, vol. 61, no. 1, pp. 88-106, 2004.

[12] X. Jin and R. W. Gereau IV, "Acute p38-mediated modulation of tetrodotoxin-resistant sodium channels in mouse sensory neurons by tumor necrosis factor- $\alpha$, Journal of Neuroscience, vol. 26, no. 1, pp. 246-255, 2006.

[13] T. M. Cunha, W. A. Verri Jr., J. S. Silva, S. Poole, F. Q. Cunha, and S. H. Ferreira, "A cascade of cytokines mediates mechanical inflammatory hypernociception in mice," Proceedings of the National Academy of Sciences of the United States of America, vol. 102, no. 5, pp. 1755-1760, 2005.

[14] C. Sommer, C. Schmidt, and A. George, "Hyperalgesia in experimental neuropathy is dependent on the TNF receptor 1," Experimental Neurology, vol. 151, no. 1, pp. 138-142, 1998.

[15] H. Loetscher, D. Stueber, D. Banner, F. Mackay, and W. Lesslauer, "Human tumor necrosis factor $\alpha$ (TNF $\alpha)$ mutants with exclusive specificity for the $55-\mathrm{kDa}$ or $75-\mathrm{kDa}$ TNF receptors," The Journal of Biological Chemistry, vol. 268, no. 35, pp. 2635026357, 1993.

[16] X. Van Ostade, P. Vandenabeele, B. Everaerdt et al., "Human TNF mutants with selective activity on the p55 receptor," Nature, vol. 361, no. 6409, pp. 266-269, 1993.

[17] G. T. Baxter, R. C. Kuo, O. J. Jupp, P. Vandenabeele, and D. J. MacEwan, "Tumor necrosis factor- $\alpha$ mediates both apoptotic cell death and cell proliferation in a human hematopoietic cell line dependent on mitotic activity and receptor subtype expression," The Journal of Biological Chemistry, vol. 274, no. 14, pp. 9539-9547, 1999.

[18] A. Leffler, R. I. Herzog, S. D. Dib-Hajj, S. G. Waxman, and T. R. Cummins, "Pharmacological properties of neuronal TTXresistant sodium channels and the role of a critical serine pore residue," Pflügers Archiv, vol. 451, no. 3, pp. 454-463, 2005.

[19] B. T. Priest, B. A. Murphy, J. A. Lindia et al., "Contribution of the tetrodotoxin-resistant voltage-gated sodium channel Nav1.9 to sensory transmission and nociceptive behavior," Proceedings of the National Academy of Sciences of the United States of America, vol. 102, no. 26, pp. 9382-9387, 2005.

[20] Z.-J. Huang and X.-J. Song, "Differing alterations of sodium currents in small dorsal root ganglion neurons after ganglion compression and peripheral nerve injury," Molecular Pain, vol. 4, article 20, 2008.

[21] R. Diem, R. Meyer, J. H. Weishaupt, and M. Bähr, "Reduction of potassium currents and phosphatidylinositol 3-kinasedependent Akt phosphorylation by tumor necrosis factor(alpha) rescues axotomized retinal ganglion cells from retrograde cell death in vivo," The Journal of Neuroscience, vol. 21, no. 6, pp. 2058-2066, 2001.

[22] K. Furukawa and M. P. Mattson, "The transcription factor NF- $\kappa \mathrm{B}$ mediates increases in calcium currents and decreases in NMDA- and AMPA/kainate-induced currents induced by tumor necrosis factor- $\alpha$ in hippocampal neurons," Journal of Neurochemistry, vol. 70, no. 5, pp. 1876-1886, 1998.

[23] B. Soliven and J. Albert, "Tumor necrosis factor modulates $\mathrm{Ca}^{2+}$ currents in cultured sympathetic neurons," Journal of Neuroscience, vol. 12, no. 7, pp. 2665-2671, 1992.

[24] S. Gudes, O. Barkai, Y. Caspi, B. Katz, S. Lev, and A. M. Binshtok, "The role of slow and persistent TTX-resistant sodium currents in acute tumor necrosis factor- $\alpha$-mediated increase in nociceptors excitability," Journal of Neurophysiology, vol. 113, no. 2, pp. 601-619, 2015.

[25] M. Schäfers, C. Sommer, C. Geis, T. Hagenacker, P. Vandenabeele, and L. S. Sorkin, "Selective stimulation of either tumor necrosis factor receptor differentially induces pain behavior in vivo and ectopic activity in sensory neurons in vitro," Neuroscience, vol. 157, no. 2, pp. 414-423, 2008.

[26] M. Guillouet, G. Gueret, F. Rannou et al., "Tumor necrosis factor- $\alpha$ downregulates sodium current in skeletal muscle by protein kinase $\mathrm{c}$ activation: involvement in critical illness polyneuromyopathy," The American Journal of Physiology-Cell Physiology, vol. 301, no. 5, pp. C1057-C1063, 2011.

[27] Y. Homma, S. J. Brull, and J.-M. Zhang, "A comparison of chronic pain behavior following local application of tumor necrosis factor $\alpha$ to the normal and mechanically compressed lumbar ganglia in the rat," Pain, vol. 95, no. 3, pp. 239-246, 2002.

[28] H. Junger and L. S. Sorkin, "Nociceptive and inflammatory effects of subcutaneous TNFalpha," Pain, vol. 85, no. 1-2, pp. 145-151, 2000.

[29] E. C. Ledgerwood, J. S. Pober, and J. R. Bradley, "Recent advances in the molecular basis of TNF signal transduction," Laboratory Investigation, vol. 79, no. 9, pp. 1041-1050, 1999.

[30] R. Tamura, T. Nemoto, T. Maruta et al., "Up-Regulation of NaV1.7 sodium channels expression by tumor necrosis factoralpha in cultured bovine adrenal chromaffin cells and rat dorsal root ganglion neurons," Anesthesia and Analgesia, vol. 118, no. 2, pp. 318-324, 2014.

[31] Z. Wu, S. Wang, S. Gruber, M. Mata, and D. J. Fink, "Full-length membrane-bound tumor necrosis factor- $\alpha$ acts through tumor necrosis factor receptor 2 to modify phenotype of sensory neurons," Pain, vol. 154, no. 9, pp. 1778-1782, 2013.

[32] M. Guillouet, G. Gueret, F. Rannou et al., "TNF $\alpha$ increases resting potential in isolated fibres from rat peroneus longus by a PKC mediated mechanism: involvement in ICU acquired polyneuromyopathy," Cytokine, vol. 56, no. 2, pp. 149-152, 2011.

[33] K. T. Murray, N. N. Hu, J. R. Daw et al., "Functional effects of protein kinase C activation on the human cardiac $\mathrm{Na}+$ channel," Circulation Research, vol. 80, no. 3, pp. 370-376, 1997.

[34] E. K. Wittmack, A. M. Rush, A. Hudmon, S. G. Waxman, and S. D. Dib-Hajj, "Voltage-gated sodium channel Nav1.6 is modulated by p38 mitogen-activated protein kinase," The Journal of Neuroscience, vol. 25, no. 28, pp. 6621-6630, 2005.

[35] G. Y. Jung, J. Y. Lee, H. Rhim, T. H. Oh, and T. Y. Yune, "An increase in voltage-gated sodium channel current elicits microglial activation followed inflammatory responses in vitro and in vivo after spinal cord injury," Glia, vol. 61, no. 11, pp. 18071821, 2013.

[36] J. Pollock, S. M. McFarlane, M. C. Connell et al., “TNF- $\alpha$ receptors simultaneously activate $\mathrm{Ca}^{2+}$ mobilisation and stress kinases in cultured sensory neurones," Neuropharmacology, vol. 42, no. 1, pp. 93-106, 2002.

[37] S. Hensellek, P. Brell, H.-G. Schaible, R. Bräuer, and G. Segond von Banchet, "The cytokine TNF $\alpha$ increases the proportion 
of DRG neurones expressing the TRPV1 receptor via the TNFR1 receptor and ERK activation," Molecular and Cellular Neuroscience, vol. 36, no. 3, pp. 381-391, 2007.

[38] L. Yu, F. Yang, H. Luo et al., "The role of TRPV1 in different subtypes of dorsal root ganglion neurons in rat chronic inflammatory nociception induced by complete Freund's adjuvant," Molecular Pain, vol. 4, article 61, 2008. 


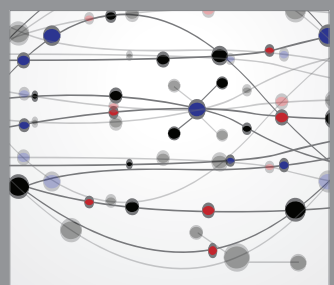

The Scientific World Journal
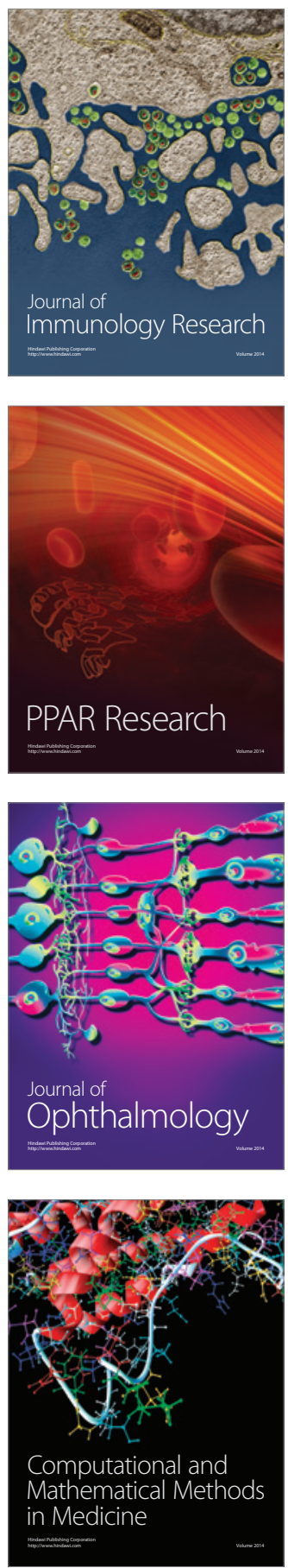

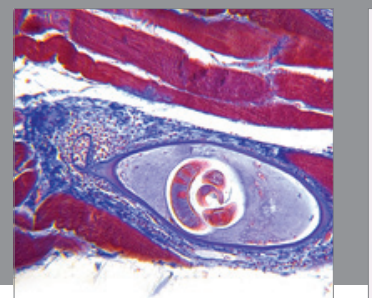

Gastroenterology

Research and Practice
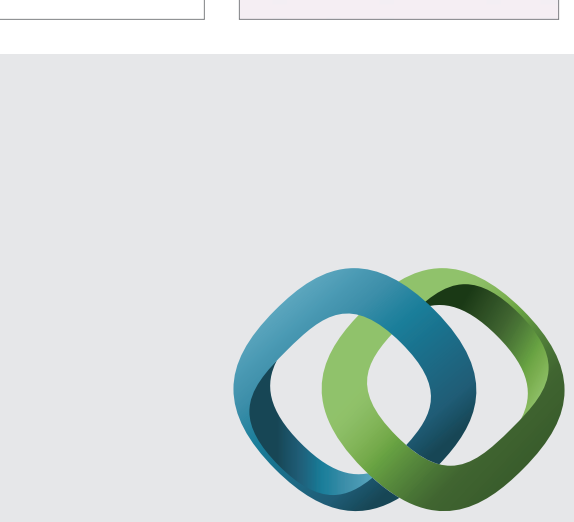

\section{Hindawi}

Submit your manuscripts at

http://www.hindawi.com
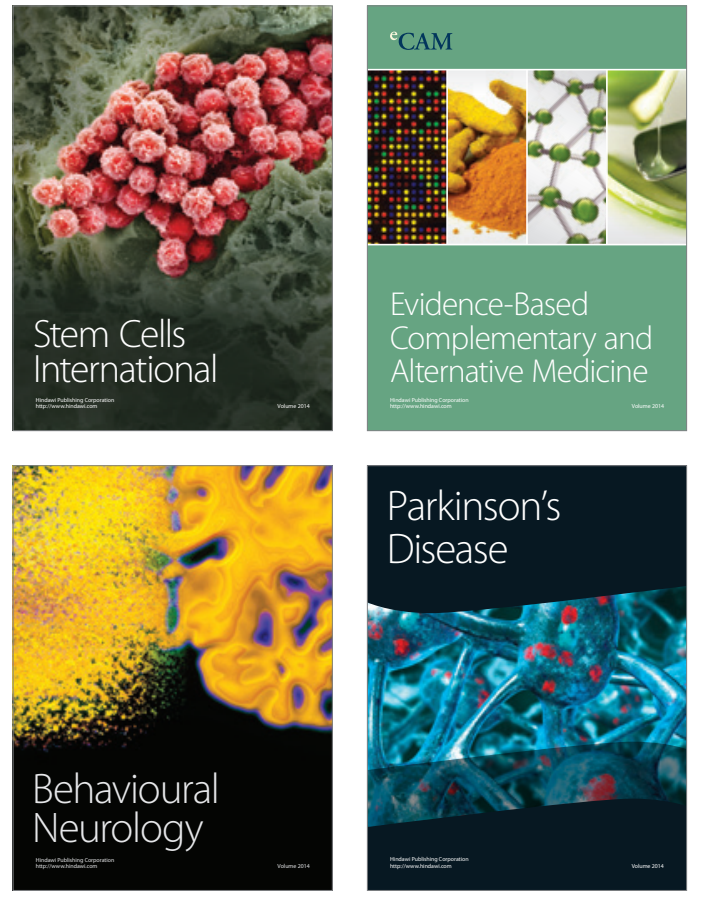
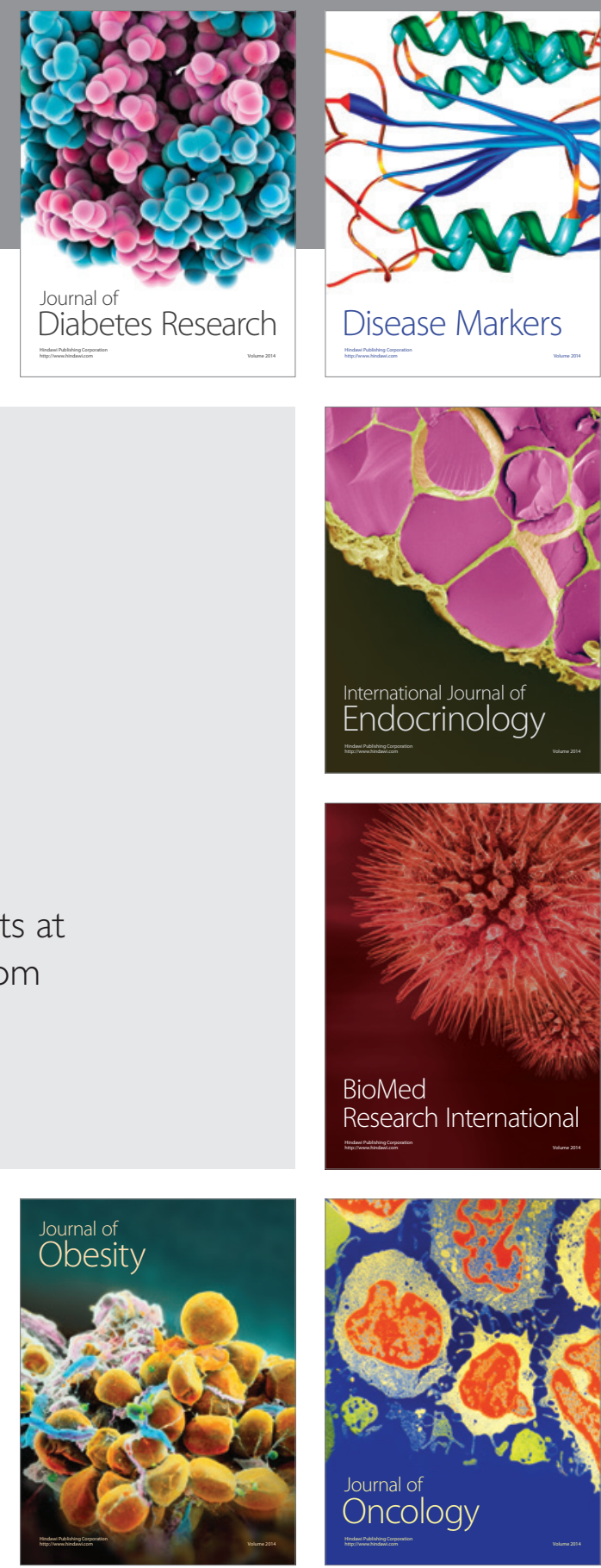

Disease Markers
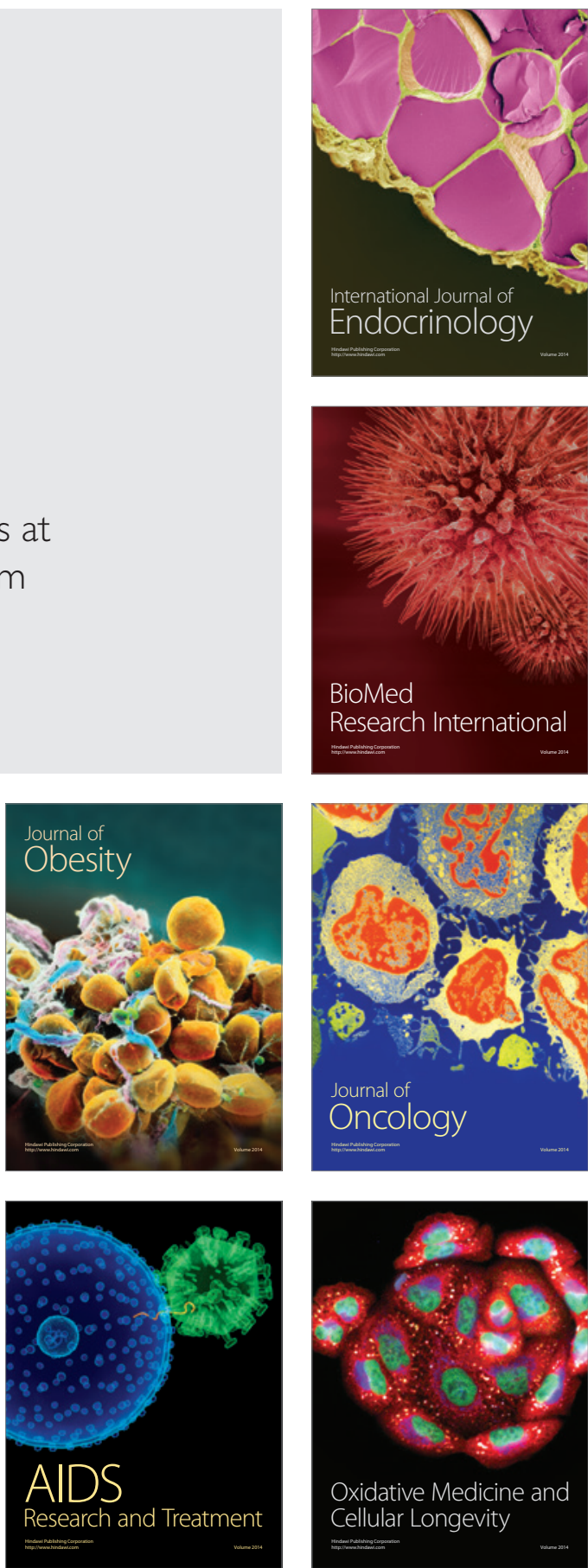